\title{
The Arctic Ocean Observation Operator for 6.9 GHz (ARC3O) - Part 1: How to obtain sea ice brightness temperatures at 6.9 GHz from climate model output
}

\author{
Clara Burgard ${ }^{1,2}$, Dirk Notz ${ }^{1,3}$, Leif T. Pedersen ${ }^{4}$, and Rasmus T. Tonboe ${ }^{5}$ \\ ${ }^{1}$ Max Planck Institute for Meteorology, Hamburg, Germany \\ ${ }^{2}$ International Max Planck Research School for Earth System Modelling, Hamburg, Germany \\ ${ }^{3}$ Institute of Oceanography, Center for Earth System Research and Sustainability, Universität Hamburg, Hamburg, Germany \\ ${ }^{4}$ National Space Institute, Technical University of Denmark, Lyngby, Denmark \\ ${ }^{5}$ Danish Meteorological Institute, Copenhagen, Denmark
}

Correspondence: Clara Burgard (clara.burgard@mpimet.mpg.de)

Received: 20 December 2019 - Discussion started: 20 January 2020

Revised: 5 June 2020 - Accepted: 17 June 2020 - Published: 23 July 2020

\begin{abstract}
We explore the feasibility of an observation operator producing passive microwave brightness temperatures for sea ice at a frequency of $6.9 \mathrm{GHz}$. We investigate the influence of simplifying assumptions for the representation of sea ice vertical properties on the simulation of microwave brightness temperatures. We do so in a one-dimensional setup, using a complex 1D thermodynamic sea ice model and a 1D microwave emission model. We find that realistic brightness temperatures can be simulated in cold conditions from a simplified linear temperature profile and a simplified salinity profile as a function of depth in the ice. These realistic brightness temperatures can be obtained based on profiles interpolated to as few as five layers. Most of the uncertainty resulting from the simplifications is introduced by the simplification of the salinity profiles. In warm conditions, the simplified salinity profiles lead to brine volume fractions that are too high in the subsurface layer. To overcome this limitation, we suggest using a constant brightness temperature for the ice during warm conditions and treating melt ponds as water surfaces. Finally, in our setup, we cannot assess the effect of wet snow properties. As periods of snow with intermediate moisture content, typically occurring in spring and fall, locally last for less than a month, our approach allows one to estimate realistic brightness temperatures at $6.9 \mathrm{GHz}$ from climate model output for most of the year.
\end{abstract}

\section{Introduction}

Sea ice concentration products are retrieved from passive microwave brightness temperatures measured by satellites and come with a non-negligible uncertainty (Ivanova et al., 2015; Tonboe et al., 2016; Lavergne et al., 2019). This observational uncertainty hinders reliable climate model initialization (Bunzel et al., 2016) and model evaluation (Notz et al., 2013). Additionally, it hinders a robust extrapolation of the future sea ice evolution based on current observations. For example, sea ice area is strongly coupled to changes in the global-mean air temperature (Gregory et al., 2002; Winton, 2011; Mahlstein and Knutti, 2012; Ridley et al., 2012; Li et al., 2013) and thus to $\mathrm{CO}_{2}$ emissions (Notz and Stroeve, 2016). The relationship between $\mathrm{CO}_{2}$ emissions, global-mean air temperature, and sea ice provides the possibility to project the future Arctic sea ice evolution under different forcing scenarios. However, Niederdrenk and Notz (2018) showed that the observational uncertainty in sea ice concentration translates into uncertainty in the sensitivity of sea ice to changes in global-mean air temperature and therefore leads to uncertainty in the temperature at which an icefree Arctic in summer can be expected.

Observation operators are a current approach in climate science to circumvent observational uncertainty and the spread introduced by the use of retrieval algorithms on satellite measurements (Flato et al., 2013; Eyring et al., 2019). They directly simulate the observable quantity, in our case 
the brightness temperature, from the climate model output instead of retrieving the simulated quantity, in our case the sea ice concentration, from the satellite observations. A sea ice observation operator reduces the uncertainty introduced by assumptions used in retrieval algorithms regarding the state of other climatic variables besides the sea ice concentration. It takes advantage of knowing the consistent climate state in time and space simulated by the climate model alongside the sea ice. This knowledge allows a more comprehensive approach to climate model evaluation, as we can not only assess the simulated sea ice concentration but also the simulated sea ice temperature, snow cover, and sea ice type. The feasibility and limitations of an observation operator applied to sea ice simulated by a climate model have not been investigated yet. This is the question we address here.

We investigate how important the complexity of the representation of sea ice properties is for the simulation of sea ice surface brightness temperatures emitted by different ice types. Experiments using a model accounting for part of the processes at work inside the sea ice combined with an emission model have shown that knowing the vertical sea ice properties is sufficient for generating realistic microwave brightness temperatures (Tonboe, 2010; Tonboe et al., 2011). We mainly concentrate on the vertical representation of temperature and salinity inside the ice and snow, as they are the main drivers of the brine volume fraction in the ice and liquid water fraction in the snow, and thus of sea ice brightness temperatures, especially at low microwave frequencies (Ulaby et al., 1986). As most general circulation models (GCMs) do not explicitly represent the time evolution of vertical profiles of temperature and salinity in the ice and snow, we investigate the effect of simplified temperature and salinity profiles on the simulation of brightness temperatures. We do so by comparing, on the one hand, reference profiles representing an estimate of reality and, on the other hand, simplified profiles representing GCM output in an idealized onedimensional setup using a complex thermodynamic sea ice model and a microwave emission model.

We focus on the simulation of sea ice brightness temperatures at $6.9 \mathrm{GHz}$ at vertical polarization as a first step. At this frequency, the main driver of brightness temperatures is the sea ice properties, while the contributions of the snow and the atmosphere due to water vapor, cloud liquid water, and temperature are small compared to the surface contribution. The framework can, however, be extended to other frequencies and polarizations in the future if the increasing importance of the snow and atmospheric contribution with increasing frequency is taken into account.

In Sect. 2, we provide the theoretical background about drivers of sea ice brightness temperatures, and in Sect. 3 we present our method and the sea ice and emission models used for our experiments. In Sect. 4, we explore the influence of simplifications in the temperature and salinity profiles on the simulation of sea ice brightness temperatures to then explore the effect of a reduced number of layers. Finally, we discuss our results in Sect. 5 and conclude with suggestions for a functional observation operator for sea ice in Sect. 6 .

\section{Theoretical background}

The brightness temperature is a measure for the microwave radiation emitted by one medium or a combination of media and corresponds to the temperature of a blackbody emitting the observed amount of radiation. It depends on the temperature distribution in the medium and the transmission and reflection affecting the path of the microwave radiation from the emitting layer within the medium to the surface of the medium. The transmission and reflection in turn depend on the properties of the medium and on the frequency and polarization of the radiation.

Transmission and reflection of the microwave radiation within an ice column are driven by the permittivity and the dielectric loss of the different layers of the ice on the one hand and scatterers present in the ice on the other hand. Sea ice is a mixture of liquid brine and pure ice and the permittivity and dielectric loss of liquid brine are orders of magnitude larger than the permittivity and dielectric loss of pure ice (Ulaby et al., 1986; Shokr and Sinha, 2015b). Therefore, the permittivity and dielectric loss inside a sea ice column are mainly a function of the fraction and distribution of liquid brine in the different layers of the ice. This means that, looking at a vertical profile of the ice, ice layers with high brine volume fractions have a lower transmissivity and larger reflectivity than ice layers with low brine volume fractions. The vertical distribution of the brine volume fraction in the ice is a function of the vertical distribution of temperature and salinity. Brine is present within the ice throughout its first year. If the ice becomes multiyear ice, most of its brine will have drained out and the brine volume fraction decreases substantially compared to first-year ice.

The scattering within an ice column is a function of the permittivity and the size of scatterers inside the ice. In firstyear ice, the main scatterers are brine pockets, while in multiyear ice the main scatterers are air bubbles, as most of the brine will have drained out (Winebrenner et al., 1992; Tonboe et al., 2006; Shokr and Sinha, 2015a).

As brightness temperatures are usually not measured at the ice surface but at the top of the atmosphere by satellites, the microwave radiation emitted by the sea ice cover can additionally be affected by transmissivity and reflectivity of the snow and atmosphere on the path between the surface and the satellite. For frequencies below $10 \mathrm{GHz}$, dry snow is practically "transparent" (Hallikainen, 1989) and the atmosphere has a negligible influence. For frequencies higher than $10 \mathrm{GHz}$, scattering occurs within a dry snowpack (Mätzler, 1987; Barber et al., 1998). In general, scattering affects the brightness temperature measured from space over sea ice surfaces increasingly when the frequency increases (Tonboe et al., 2006) as the wavelength successively approaches the 
size of brine pockets and air bubbles on the order of tenths of a millimeter to millimeters, snow grains on the order of hundreds of micrometers to millimeters, and atmospheric aerosols and droplets on the order of micrometers.

If the snow becomes wet, as happens during melting periods and localized events of warm air advection that mainly occur in spring and fall, the dielectric loss in the snow layers increases substantially, leading to a reduction in the transmissivity of the snow layer to microwave radiation. This may also happen when brine-wicking takes place in the lowest layer of the snow, especially above first-year ice (Barber et al., 1998; Shokr and Sinha, 2015b). However, we will not attempt to investigate the effect of wet snow on the radiation in detail in this study as our model setup does not allow us to simulate detailed processes within the snowpack.

Sea ice concentration retrievals are based on satellite measurements at frequencies ranging from 1.4 to $91 \mathrm{GHz}$ (Ivanova et al., 2014, 2015; Gabarro et al., 2017). In the following, we concentrate on radiation at $6.9 \mathrm{GHz}$ and vertical polarization. This frequency is advantageous as with a wavelength of approx. $4.3 \mathrm{~cm}$ it is only slightly affected by scattering inside the ice, snow, and atmosphere. The brightness temperature at $6.9 \mathrm{GHz}$ therefore mainly depends on the properties affecting permittivity and dielectric loss of the different layers inside the ice. This is why our focus lies on the properties of the sea ice column, rather than on the snow structure or the state of the atmosphere. The penetration depth in ice at $6.9 \mathrm{GHz}$ is around $20 \mathrm{~cm}$ for first-year ice and around $50 \mathrm{~cm}$ for multiyear ice (Tonboe et al., 2006). Therefore, we investigate not only the properties of the ice surface but also the properties of the whole sea ice column to be sure to capture the main influences on the brightness temperature.

\section{Methods and data}

Although a few GCMs use detailed sea ice modules (Vancoppenolle et al., 2009; Bailey et al., 2018), most GCMs use very simple sea ice models that do not resolve the properties driving microwave transmission and reflection inside the ice and snow. Ideally, our observation operator would compute brightness temperatures from such a GCM as well. However, it is not clear yet how these simplifications affect a brightness temperature simulated based on a simple representation of the relevant properties.

As a basis to investigate the effect of using non-detailed sea ice information, we assume that our input for the operator would be output by the Max Planck Institute Earth System Model (MPI-ESM, Wetzel et al., 2012). In MPI-ESM, sea ice is represented as flat sea ice, with very simple sea ice properties: a sea ice (bare ice) or snow (snow-covered ice) surface temperature, a constant sea ice bottom temperature at $-1.8^{\circ} \mathrm{C}$, and a constant salinity of $5 \mathrm{~g} \mathrm{~kg}^{-1}$ regardless of sea ice type or age (Notz et al., 2013).

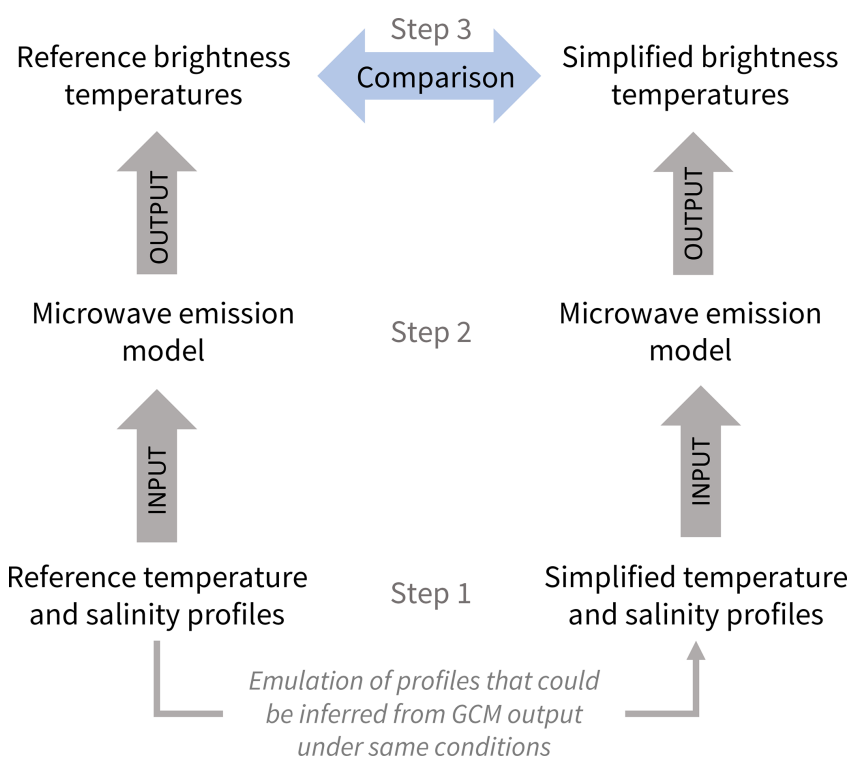

Figure 1. Schematic of the steps of our simulation and comparison method.

To explore the importance of the vertical distribution of sea ice properties on the simulation of brightness temperatures, we use an idealized one-dimensional setup. This onedimensional setup works as follows. On the one hand, we use a one-dimensional thermodynamic sea ice model to simulate our reference profiles (see Sect. 3.1). It computes highly resolved vertical sea ice profiles under a given atmospheric forcing. On the other hand, we simplify these reference profiles to emulate profiles that could be inferred from information given by MPI-ESM for the same conditions. These two sets of profiles can be used to simulate two sets of brightness temperatures with a microwave emission model (see Sect. 3.2). The two sets of resulting brightness temperatures can then be used to quantify the effect of the GCM simplification on the brightness temperature simulation compared to our reference (see Fig. 1, Sect. 3.3, and 3.4).

In this setup, we can quantify the influence of each parameter separately on the simulated brightness temperature. This a necessary first step to understand fundamental drivers of the brightness temperature before comparing brightness temperatures simulated on the basis of MPI-ESM output directly to brightness temperatures measured by satellites, which we do in Burgard et al. (2020).

\subsection{SAMSIM}

Our reference profiles are simulated by the 1D SemiAdaptive Multi-phase Sea Ice Model (SAMSIM, Griewank and Notz, 2013, 2015). This is a complex thermodynamical model simulating the evolution of a 1D sea ice column under given surface forcing. It computes sea ice temperature, salinity, and brine volume fraction profiles on a semi-adaptive grid with a number of layers varying between 0 and 100 . 
It includes most of the processes governing sea ice growth and melt and interactions between the ice and, if existent, its snow cover. It was developed to investigate the brine dynamics inside the ice. A detailed description of underlying equations and represented processes can be found in Griewank and Notz (2013) and Griewank and Notz (2015).

We force SAMSIM with $2 \mathrm{~m}$ air temperature, surface downward longwave radiation, surface downward shortwave radiation, and precipitation from the ERA-Interim reanalysis (Dee et al., 2011) in the time period from July 2005 to December 2009. This gives us insight into 4.5 annual cycles, so that we can assess the interannual variability of the growth and melt of sea ice and the evolution of its properties. The ocean salinity is kept at $34 \mathrm{~g} \mathrm{~kg}^{-1}$ and the oceanic heat flux at the bottom of the ice is derived from Surface Heat Budget of the Arctic Ocean Experiment (SHEBA) measurements, varying between $0 \mathrm{~W} \mathrm{~m}^{-2}$ in spring and $14 \mathrm{~W} \mathrm{~m}^{-2}$ in autumn (Huwald et al., 2005; Griewank and Notz, 2015).

We conduct our analysis using atmospheric forcing from two random points in the Arctic Ocean as input for SAMSIM. At the first point, the combined forcing of the ERAInterim atmospheric variables and the SHEBA oceanic flux leads to complete melting of the simulated ice in summer each year, resulting in several cycles of first-year ice. At the second point, the combination of the atmospheric forcing and oceanic heat flux leads to a simulated ice cover present throughout the year, resulting in several cycles of multiyear ice (Fig. 2). This way, we capture potential differences in the brightness temperature simulation depending on the ice type. To ensure that the conclusions we draw from these two random points are robust, we have conducted the same analysis on five additional random points distributed in the Arctic Ocean and find that the results support our conclusions.

\subsection{MEMLS}

The simulation of sea ice brightness temperatures is conducted with a slightly modified version of the Microwave Emission Model for Layered Snowpacks (MEMLS) extended to sea ice (Tonboe et al., 2006). MEMLS was first developed by Wiesmann and Mätzler (1999) to simulate brightness temperatures emitted by a snowpack composed of several layers and was later extended to sea ice (Tonboe et al., 2006). MEMLS uses the information of the properties of the ice and snow layers to simulate the path of microwave radiation from the bottom to the surface of the ice and, if present, snow. It uses the thickness, the temperature, the salinity, the density, the correlation length (a measure for the scatterer size), the wetness, the brine pocket form, and information about the type of medium (snow, first-year ice, and multiyear ice) of the different sea ice and snow layers to compute transmission and reflection of the radiation along the path. This then results in a brightness temperature emitted at the surface of the ice or snow.
We do not take into account the atmosphere in our analysis, as its effect is relatively small at $6.9 \mathrm{GHz}$. The use of the term "brightness temperatures" in the following is therefore equivalent to the use of "brightness temperatures emitted at the surface of the ice and snow column".

\subsection{General simulation setup}

The temperature and salinity profiles produced by SAMSIM are used as input for MEMLS for the simulation of brightness temperatures. Additionally, density profiles are derived from temperature and salinity using relationships given by Notz (2005) (see Eq. A5). Next to the temperature, salinity, and density profiles, other variables, which are not computed by SAMSIM, have to be provided to MEMLS. These are the correlation length, the brine pocket form, the incidence angle, the ocean temperature, the incoming microwave radiation from the atmosphere (i.e., the cosmic background radiation and the radiation reflected and emitted by properties of the atmosphere), and the ice ocean reflectivity for vertical polarization. They are set to constants, which are listed in Table 1.

Additionally, except for snow thickness and temperature, snow properties are resolved neither in SAMSIM nor in MPIESM. Although a dry snow cover is practically transparent at frequencies lower than $10 \mathrm{GHz}$ (Hallikainen, 1989), we still need to account for its presence due to one indirect and one direct effect on the brightness temperature. On the one hand, the snow cover leads to the thermal insulation of the ice column and therefore affects the temperature profile inside the ice, which in turn affects the brightness temperature. On the other hand, the difference in density between ice, snow, and atmosphere leads to refraction of the radiation at the interface between ice and snow and between snow and atmosphere. The former effect is taken into account through the use of the SAMSIM snow thickness and snow temperature evolution, and the latter is taken into account through the snow thickness and by using a low density for snow compared to ice. We therefore set all snow properties, except the snow temperature and snow thickness, to constants, also listed in Table 1.

The effect of wet snow on the brightness temperature is larger and depends on the snow wetness, brine-wicking, and snow metamorphism. As neither SAMSIM nor MPI-ESM resolve these properties in the snow, we set the snow wetness to zero in this idealized study. However, when comparing results of a possible observation operator based on this study to actual observations, we strongly recommend not considering periods of wet snow during melting periods and events of warm air advection, as setting the snow wetness to zero will lead to implausible brightness temperatures in these periods.

Our input for the emission model, e.g., salinity, correlation length, and brine pocket form, comes with uncertainties. These are mainly caused by a partial or complete lack of in situ observations of these small-scale properties and 


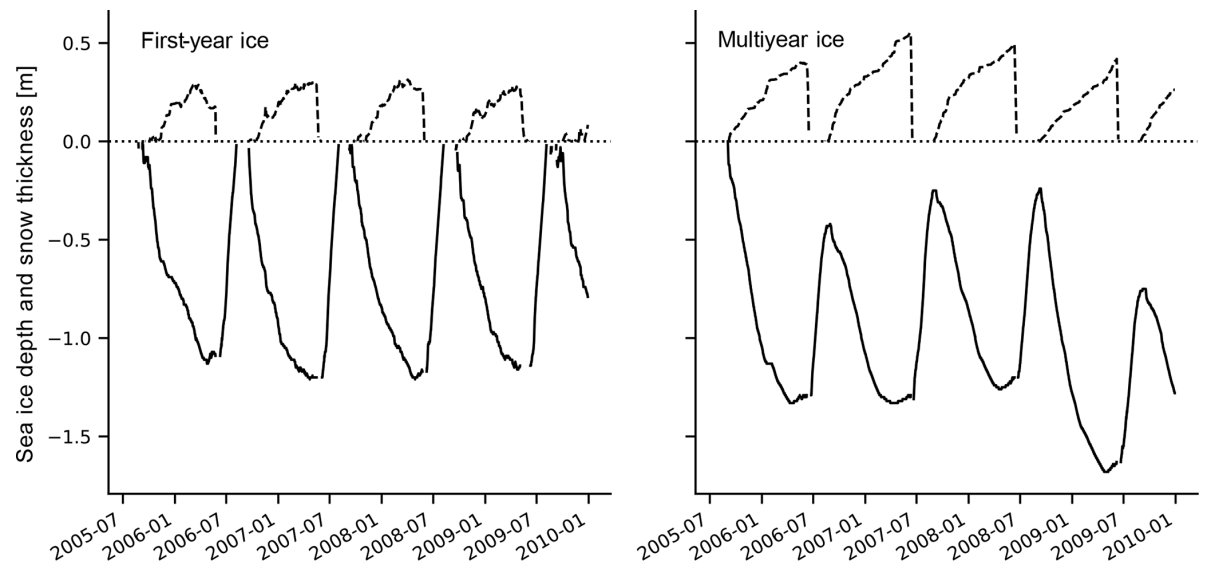

Figure 2. Evolution of sea ice (solid line) and snow (dashed line) thickness as simulated by SAMSIM under ERA-Interim forcing between July 2005 and December 2009. We use ERA-Interim forcing from $75^{\circ} \mathrm{N}, 0^{\circ} \mathrm{W}$ for the first-year ice and from $90^{\circ} \mathrm{N}$ for multiyear ice. Note that to avoid unrealistic model artifacts in the ice thickness, we have masked out the few timesteps following the final phase of the melting of the snow cover. Also note that the same analysis was conducted using atmospheric forcing from the points $74^{\circ} \mathrm{N}, 170^{\circ} \mathrm{E} ; 77^{\circ} \mathrm{N}, 39^{\circ} \mathrm{E}$; $80^{\circ} \mathrm{N}, 160^{\circ} \mathrm{W} ; 82^{\circ} \mathrm{N}, 120^{\circ} \mathrm{W}$; and $85^{\circ} \mathrm{N}, 50^{\circ} \mathrm{W}$ (not shown) to ensure the robustness of our results.

Table 1. MEMLS constant input details and properties of the snow layer. The incidence angle is from AMSR-E and AMSR2, which are passive microwave sensors measuring at $6.9 \mathrm{GHz}$ (NASDA, 2003; JAXA, 2011). The ocean temperature and snow density are the constant values used in a GCM such as MPI-ESM (Wetzel et al., 2012; Giorgetta et al., 2013). The incoming microwave radiation from the atmosphere is set to $0 \mathrm{~K}$ because we want to focus on the effect of sea ice properties on the emitted radiation. Correlation lengths are based on past experiments conducted by Rasmus T. Tonboe.

\begin{tabular}{ll}
\hline Incidence angle & $55^{\circ}$ \\
Ocean temperature & $-1.8^{\circ} \mathrm{C}$ \\
Incoming microwave radiation from the atmosphere & $0 \mathrm{~K}$ \\
Ice ocean reflectivity for V polarization & 0.25 \\
Brine pocket form & spherical \\
Correlation length first-year ice & $0.35 \mathrm{~mm}$ for depth $<20 \mathrm{~cm}$, \\
& $0.25 \mathrm{~mm}$ for depth $>20 \mathrm{~cm}$ \\
Correlation length multiyear ice & $1.5 \mathrm{~mm}$ \\
\hline Snow thickness & as computed by SAMSIM \\
Snow density & $300 \mathrm{~kg} \mathrm{~m}^{-3}$ \\
Snow correlation length & $0.15 \mathrm{~mm}$ \\
Snow salinity & $0 \mathrm{~g} \mathrm{~kg}^{-1}$ \\
Snow temperature & as computed by SAMSIM \\
\hline
\end{tabular}

the resulting low understanding of their evolution. We therefore recommend more observations of the ice properties, ideally combined with concurrent microwave radiation measurements. A few such observations exist already, from both laboratory and in situ settings, but they mainly focus on frequencies higher than $6.9 \mathrm{GHz}$ (e.g., Grenfell et al., 1998; Jezek et al., 1998; Perovich et al., 1998; Hwang et al., 2007). With more combined observations at lower frequencies, we expect that the uncertainty in the brightness temperature simulation can be reduced in the future through further research and better understanding of the components introducing the uncertainty.

For example, a better understanding of the sea ice salinity evolution would be of advantage. The salinity parametriza- tion used in Sect. 4.2.2 is based on an "L shape" of the salinity profile, while the sea ice salinity profile often resembles a "C shape" or even a " $\Gamma$ shape" when cold temperatures prevail (Nakawo and Sinha, 1981; Shokr and Sinha, 2015a). Another parameter of uncertainty is the correlation length. Although it is a variable that is quite well understood and quantifiable for snow (Mätzler, 2002; Proksch et al., 2015; Lemmetyinen et al., 2018), its quantification in sea ice is not clear and its values not well known. On a similar note, MEMLS uses assumptions about the form of the brine pockets. Here, we assume spherical brine pockets. However, it is known that the brine pocket form depends highly on the initial formation process of the ice, which is not simulated. In any case, we assume that the choice of brine pocket form will 
not affect our result substantially because scattering within the ice is negligible at $6.9 \mathrm{GHz}$.

Another limitation in the input data for MEMLS is the snow information. We investigated the indirect effect of the snow cover on the simulated brightness temperature, e.g., the radiative effect (as opposed to the thermal insulation effect), and found that the brightness temperature decreases by approximately $0.13 \mathrm{~K}$ for every centimeter of snow present on the ice column. Therefore, although the snow is expected to be "transparent" at less than $10 \mathrm{GHz}$, lack of information about the snow structure besides snow temperature and thickness might still lead to uncertainties of up to a few kelvin in the presence of a thick snow cover.

Finally, the use of MEMLS as a sea ice emission model is a source of uncertainty as well. Here again, the lack of measurements of the parameters needed for the brightness temperature simulation and of microwave radiation itself has inhibited a comprehensive evaluation of the sea ice version of MEMLS simulations against reality. Still, it is accepted as one of the main tools for sea ice brightness temperature simulations and has shown its strength in several previous studies (Tonboe, 2010; Tonboe et al., 2011; Willmes et al., 2014; Lee et al., 2017).

However, the uncertainties listed above only have a limited impact on the present study. We concentrate on a relative comparison, where we change temperature and salinity in the ice to understand their impact on the brightness temperature, but assumptions about the snow and ice correlation length, the form of brine pockets, and the snow density are the same in our reference and our simplified brightness temperature simulations. The uncertainties will therefore not impact the difference between the two sets of brightness temperatures. Additionally, in regard to the absolute values, Burgard et al. (2020) show that realistic brightness temperatures can be simulated by MEMLS using the above-mentioned uncertain assumptions with slight tuning. The effect of the uncertainties therefore remains small when considering large scales.

\subsection{Experiments}

The aim of this study is to assess if realistic brightness temperatures can be simulated for $6.9 \mathrm{GHz}$ vertical polarization, using the limited information about sea ice properties provided by a GCM such as MPI-ESM. This assessment is conducted through a range of experiments. In a first step (see Sect. 4.1), we investigate the influence of the ice surface and subsurface properties on the radiation emitted by the snowice column. We examine in which conditions information about the vertical profile is needed for realistic brightness temperatures to be simulated and in which conditions information about surface and subsurface properties is sufficient.

In a second step (see Sect. 4.2), we examine the effect of assuming a linear temperature profile and of different assumptions for the simplification of the salinity profile on the simulated brightness temperature. In this set of experiments, we compare brightness temperatures simulated based on SAMSIM profiles (referred to in the following as reference profiles) and brightness temperatures simulated based on the simplified profiles. The simplified input profiles are interpolated to the same number of layers as the reference profiles (ranging from 1 to 100 layers, depending on the ice thickness).

In a third step (see Sect. 4.3), we examine the effect of reducing the vertical resolution on the simulated brightness temperature. To do so, we interpolate the vertical properties on fewer layers than the reference profiles.

\section{Results}

\subsection{Subsurface properties vs. vertical profile}

Sea ice brightness temperatures at $6.9 \mathrm{GHz}$ are mainly driven by the distribution of liquid brine inside the ice, as the permittivity and dielectric loss of the ice layers play a larger role than scattering at this frequency. We compute the brine volume fraction with Eq. (A4) based on the ice temperature and salinity profiles given by SAMSIM. Comparing the ice subsurface brine volume fraction, i.e., in the top ice layer (upper $1 \mathrm{~cm}$ ) of the profiles, with the simulated reference brightness temperatures, the relationship between brine volume fraction and brightness temperature is clearly visible. The brightness temperatures show a strong dependence on the ice subsurface brine volume fraction (Fig. 3, top row). If we concentrate the brightness temperature simulation on the ice layers, i.e., using only the properties of the ice layers of the snow and ice column as input to MEMLS, the slight offset in the brightness temperature introduced by the refraction due to the snow cover is removed and the relationship is even clearer (Fig. 3, bottom row).

When the ice subsurface brine volume fraction is higher than 0.2 , the brightness temperature from the ice column is linearly related to the ice subsurface brine volume fraction (Fig. 3, bottom row). This means that no radiation signal from below the subsurface layer influences the brightness temperature and that only the brine volume fraction in the upper centimeters of ice matters. The brightness temperature varies roughly linearly between brightness temperatures typical for ice $(\approx 260 \mathrm{~K})$ at an ice subsurface brine volume fraction of 0.2 and brightness temperatures typical for open water $(\approx 160 \mathrm{~K})$ at an ice subsurface brine volume fraction of 1 . In our SAMSIM profiles, these high subsurface brine volume fractions occur predominantly in warm conditions, i.e., from April to September, during the melting period and in the beginning of the freezing season. We therefore suggest that an ice subsurface brine volume fraction above 0.2 can be interpreted both as very wet ice or as a measure for the melt pond fraction. This strong relationship means that, when the brine volume fraction is above 0.2 , the subsurface properties play 


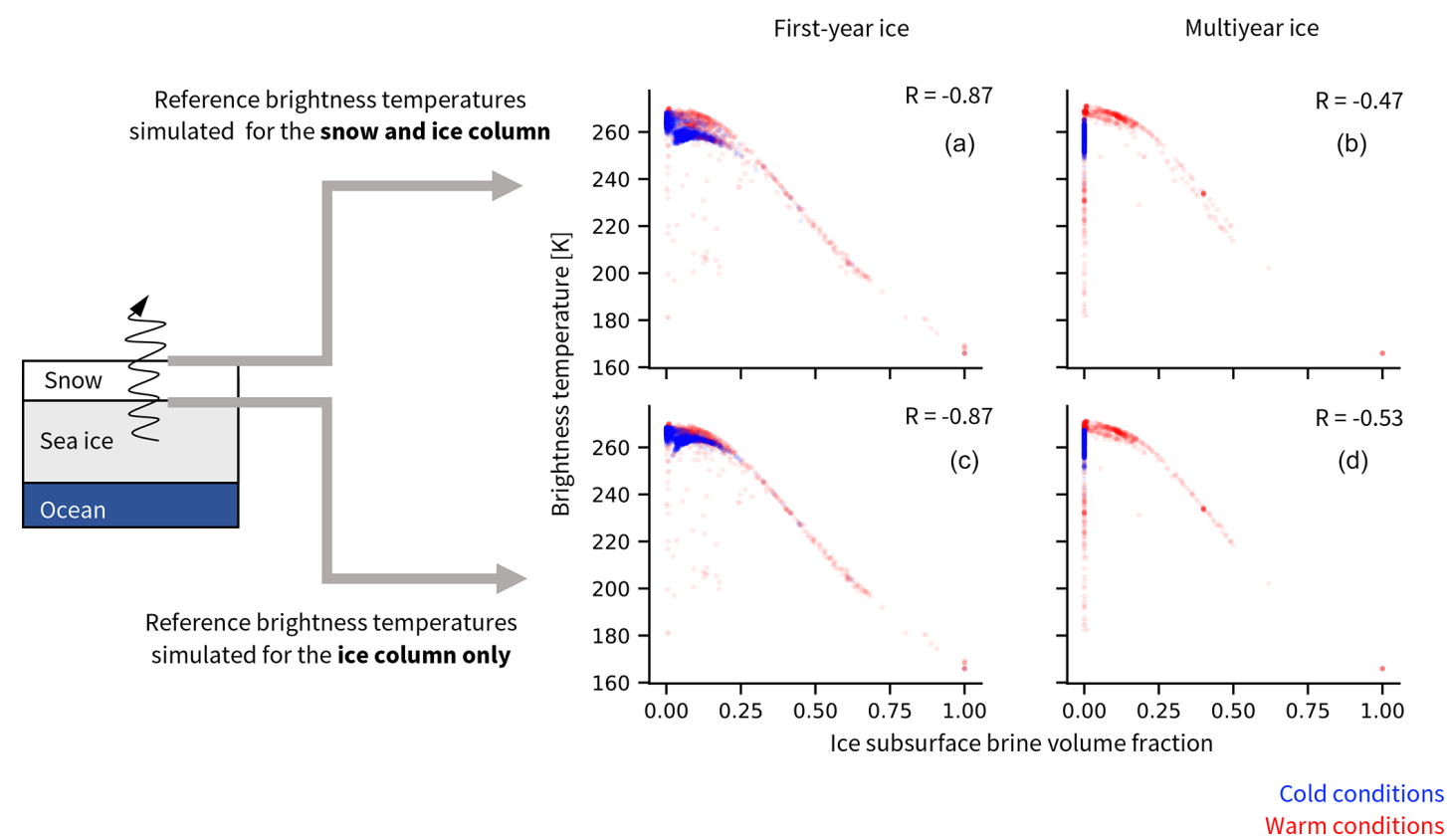

Figure 3. Reference brightness temperatures at $6.9 \mathrm{GHz}$ vertical polarization, simulated based on properties simulated by SAMSIM for the ice and snow column $(\mathbf{a}, \mathbf{b})$ and on the ice column only $(\mathbf{c}, \mathbf{d})$, as a function of the reference ice subsurface brine volume fraction for first year-ice (a, c) and multiyear ice $(\mathbf{b}, \mathbf{d})$. Blue represents cold conditions (October to March), and red represents warm conditions (April to September). $R$ is the correlation coefficient between the brightness temperature and the ice subsurface brine volume fraction.

the main role for the brightness temperature simulation and vertical properties are not necessarily needed.

In some multiyear ice cases during warm conditions, the brightness temperature drops below $240 \mathrm{~K}$ at near-zero subsurface brine volume fractions. These low brightness temperatures occur in September, in the first two or three weeks in which ice growth sets in again. In these cases, the ice column used as input for MEMLS has a brine volume fraction of zero over the whole column, except in the bottom layer. We therefore suggest that the simulated brightness temperature is mainly influenced by the very saline bottom layer at the interface between ice and ocean in these cases, leading to low brightness temperatures. This behavior is not necessarily realistic and the conditions leading to these input salinity profiles might need further investigation.

Otherwise, for subsurface brine volume fractions below 0.2 , occurring in both cold and warm conditions, the brightness temperatures vary by 10 to $15 \mathrm{~K}$ around $260 \mathrm{~K}$ for similar ice subsurface brine volume fractions. For these low ice subsurface brine volume fractions, the brightness temperatures are driven by the distribution of brine further inside the ice, which is a function of the temperature and salinity distribution. Unfortunately, for these brightness temperatures around $260 \mathrm{~K}$ at low ice subsurface brine volume fractions, we could not infer a direct relationship between the brightness temperature and a given layer or a given brine volume fraction inside the ice from our data. This implies that information about the vertical distribution of temperature and salinity (and consequently brine volume fraction) throughout the ice column is necessary to simulate realistic brightness temperatures.

From this first look at the relationship between ice properties and simulated brightness temperatures, we conclude that information about the vertical profiles of brine volume fraction are necessary for the simulation of brightness temperatures for cold conditions and for parts of the warm conditions. The effect of describing the brine volume fraction profiles through simplified temperature and salinity profiles on the brightness temperature simulation is what we investigate in the next step.

\subsection{Simplifying the temperature and salinity profile}

The brightness temperature emitted by a snow and ice column is mainly driven by the distribution of the brine volume fraction in the ice column. As the brine volume fraction can be described as a function of temperature and salinity, we now investigate the effect of reduced information availability about these profiles, as would be the case in GCM output, on the simulated brightness temperatures.

\subsubsection{Simplifying the temperature profile}

We start by investigating the brightness temperature simulated based on a temperature profile as could be inferred from MPI-ESM output. We call this experiment SIMPLETEMP. MPI-ESM computes a sea ice (bare ice) or snow (snow- 


\section{EXPERIMENT SIMPLETEMP}

- linear temperature profile

- reference salinity profile

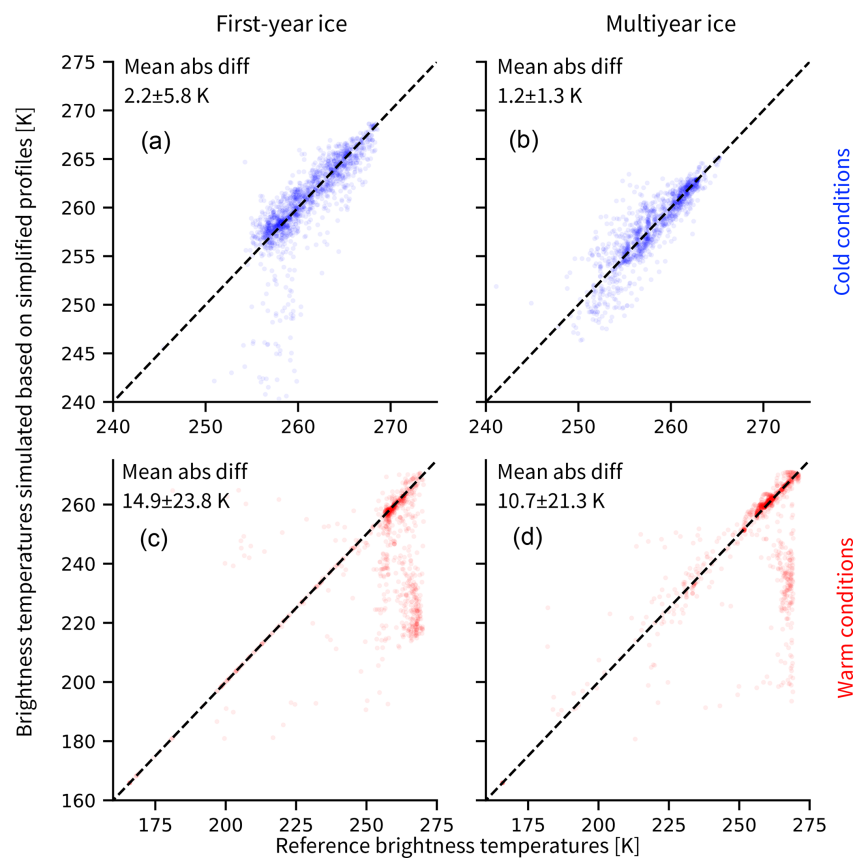

Figure 4. Brightness temperatures at $6.9 \mathrm{GHz}$ vertical polarization, simulated based on linear temperature profiles and reference salinity profiles (experiment SIMPLETEMP), as a function of reference brightness temperatures: (a, c) first-year ice and (b, d) multiyear ice in (a, b) cold conditions (October to March) and (c, d) warm conditions (April to September). Note that the axes for cold conditions are limited to the range between 240 to $275 \mathrm{~K}$ for clarity. The remaining brightness temperatures are scattered between 165 and $240 \mathrm{~K}$ and represent around $2 \%$ of the simplified data and $0.4 \%$ of the reference data.

covered ice) surface temperature and a constant sea ice bottom temperature at $-1.8^{\circ} \mathrm{C}$. Therefore, we suggest using a two-step linear profile through snow and ice. We use the snow surface temperature as simulated by SAMSIM and infer the ice temperature at the interface between ice and snow from it, following Eq. (A6). From this ice surface temperature, we interpolate the temperature profile linearly to the ice bottom layer, which has a temperature of $-1.8^{\circ} \mathrm{C}$.

The influence of the simplifications is clearly different depending on the season. We therefore divide our results into cold conditions (October to March; see Fig. 4, top row) and warm conditions (April to September, see Fig. 4, bottom row). In cold conditions, the absolute difference between brightness temperatures simulated from simplified profiles and brightness temperatures simulated from reference profiles remains small for both first-year ice $(2.2 \pm 5.8 \mathrm{~K})$ and multiyear ice $(1.2 \pm 1.3 \mathrm{~K})$. In warm conditions, this absolute difference increases by approximately an order of magnitude to $14.9 \pm 23.8 \mathrm{~K}$ (first-year ice) and $10.7 \pm 21.3 \mathrm{~K}$ (multiyear

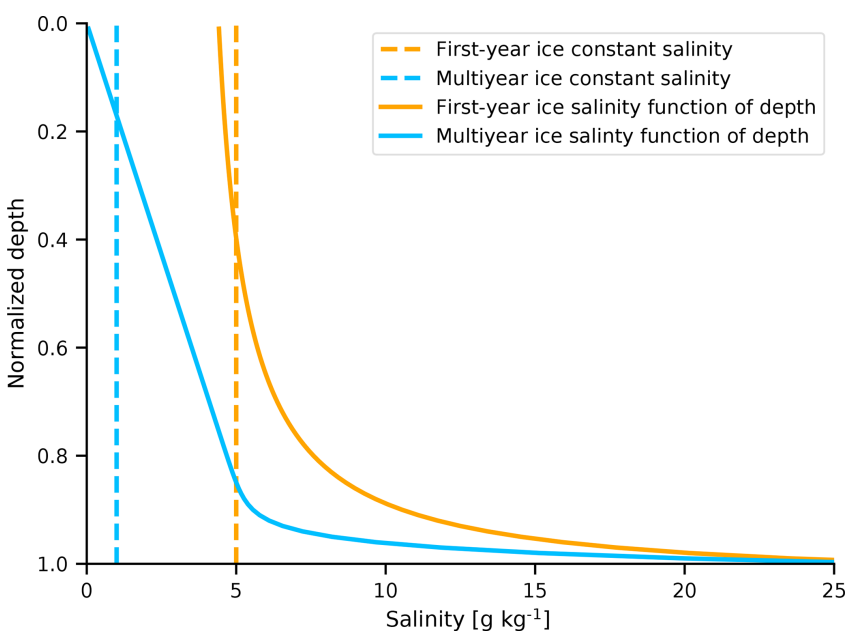

Figure 5. Salinity profiles used for the simplified profiles in Sect. 4.2.2. The dashed lines represent the constant salinity profiles and the solid lines represent the salinity profiles as a function of depth. The colors represent the different ice types.

ice). The assumption of a two-step linear temperature profile in the snow and ice therefore does not introduce large uncertainties in the brightness temperature simulation in cold conditions but should be used with care in warm conditions.

\subsubsection{Simplifying the salinity profile}

In the experiment SIMPLESALCONST, we explore the effect of a constant salinity profile on the simulated brightness temperature. MPI-ESM assumes a constant salinity of $5 \mathrm{~g} \mathrm{~kg}^{-1}$ regardless of sea ice type or age. As this is clearly too high for multiyear ice (Ulaby et al., 1986), we assume a constant salinity of $5 \mathrm{~g} \mathrm{~kg}^{-1}$ for first-year ice and a constant salinity of $1 \mathrm{~g} \mathrm{~kg}^{-1}$ for multiyear ice throughout the ice column in our simplified salinity profiles (see dashed lines in Fig. 5).

In the parallel experiment SIMPLESALFUNC, we explore an alternative approach to simplify salinity profiles. We use a parametrization representing salinity as a function of depth (Griewank and Notz, 2015). This parametrization assumes an L-shaped profile, with low salinity near the surface and a rapidly increasing salinity in the lower ice layers (see solid lines in Fig. 5 and Table B1). This parametrization has been evaluated against observations (Griewank and Notz, 2015). In both SIMPLESALCONST and SIMPLESALFUNC, we use the reference temperature profiles simulated by SAMSIM.

Again, we divide the results depending on the season. While, for first-year in cold conditions, the effect of using a constant salinity (SIMPLESALCONST) is as low as using a linear temperature profile, with an absolute difference between the brightness temperatures based on simplified profiles and the reference brightness temperature of $2.5 \pm 6.5 \mathrm{~K}$, the absolute difference reaches $6.6 \pm 4.3 \mathrm{~K}$ for multiyear ice 
(a) EXPERIMENT SIMPLESALCONST

- reference temperature profile

- constant salinity profile (b) EXPERIMENT SIMPLESALFUNC

- reference temperature profile

- salinity profile as a function of depth
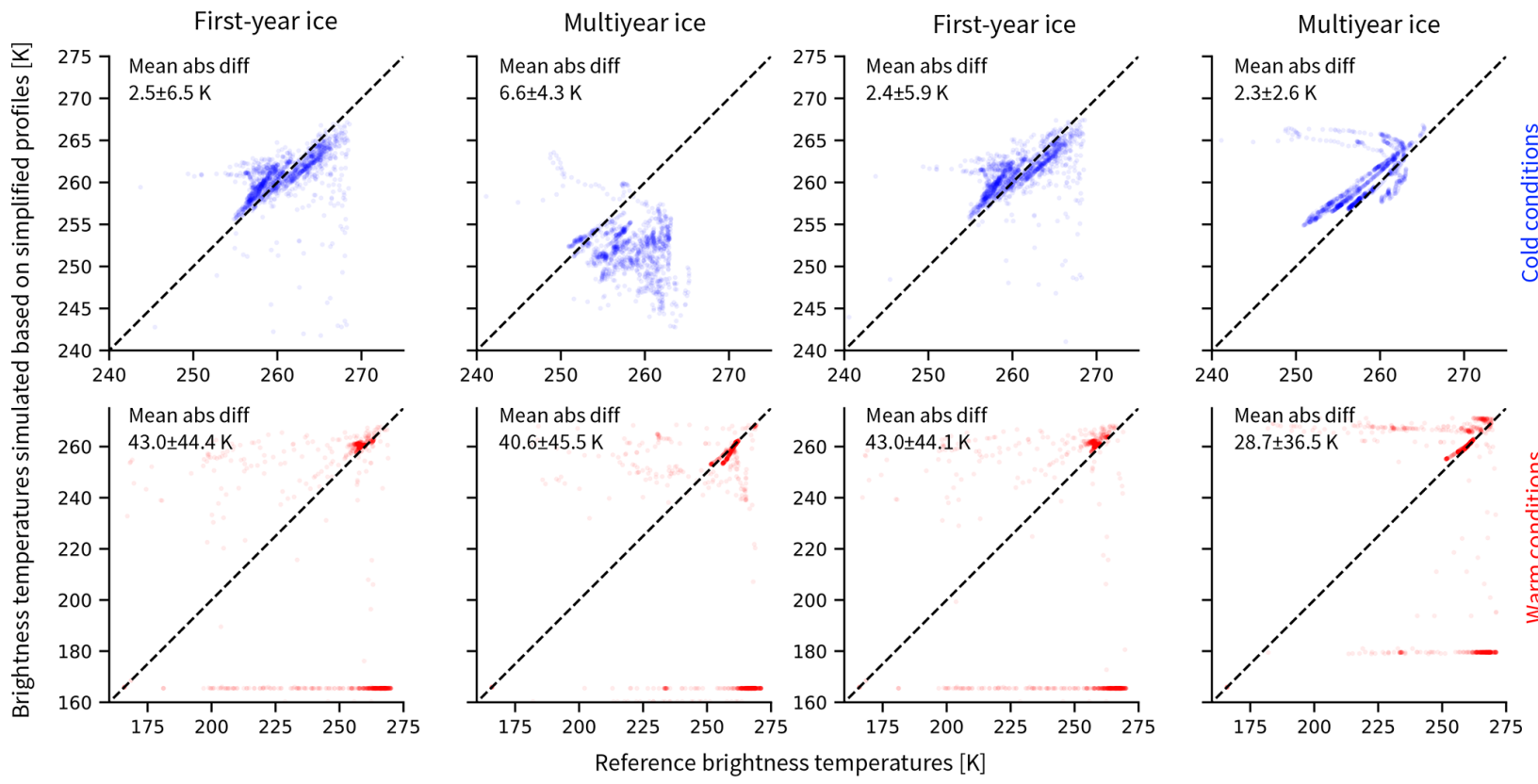

\section{듬}

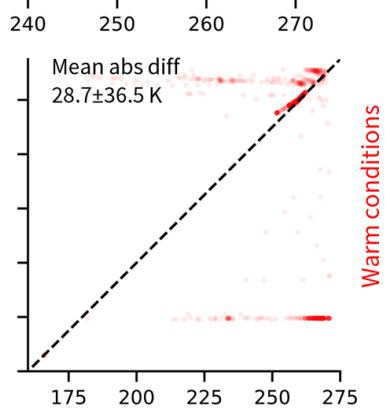

Figure 6. Brightness temperatures at $6.9 \mathrm{GHz}$ vertical polarization, simulated based on reference temperature profiles and (a) constant salinity profiles (experiment SIMPLESALCONST) or (b) salinity profiles as a function of depth (experiment SIMPLESALFUNC) as a function of reference brightness temperatures. The first and third columns show first-year ice. The second and fourth columns show multiyear ice. The upper row shows cold conditions (October to March), and the lower row shows warm conditions (April to September). Note that the axes for cold conditions are limited to the range between 240 to $275 \mathrm{~K}$ for clarity. The remaining brightness temperatures are scattered between 165 and $240 \mathrm{~K}$ and represent around $2 \%$ of the simplified data and $0.4 \%$ of the reference data.

(Fig. 6a, top row). In warm conditions, the mean absolute differences are an order of magnitude higher, $43.0 \pm 44.4 \mathrm{~K}$ for first-year ice and $40.6 \pm 45.5 \mathrm{~K}$ for multiyear ice (Fig. 6a, bottom row).

If the brightness temperature is simulated based on reference temperature profiles and on the salinity profiles as a function of depth (SIMPLESALFUNC, Fig. 6b), the uncertainty is similar to the uncertainty introduced by using a constant salinity profile for first-year ice $(2.4 \pm 5.9 \mathrm{~K}$ in cold conditions and $43.0 \pm 44.1 \mathrm{~K}$ in warm conditions). However, for multiyear ice, the uncertainty introduced by using salinity profiles as a function of depth is lower than the uncertainty introduced by assuming that the salinity is constant throughout depth $(2.3 \pm 2.6 \mathrm{~K}$ in cold conditions and $28.7 \pm 36.5 \mathrm{~K}$ in warm conditions). We therefore recommend using an ice salinity profile as a function of depth rather than a constant salinity profile as a simplification.

\subsubsection{Combining simplified temperature and salinity profiles}

In the experiments SIMPLETEMP, SIMPLESALCONST, and SIMPLESALFUNC, we learned about the individual ef- fects of using simple temperature and salinity profiles on the brightness temperature simulation. To confirm the conclusion that using both a linear temperature profile and a salinity profile as a function of depth will lead to realistic brightness temperatures, we conduct two additional experiments, combining our simplifications. In the experiment SIMPLEALLCONST, we combine a linear temperature profile and a constant salinity profile. In the experiment SIMPLEALLFUNC, we combine a linear temperature profile and a salinity profile as a function of depth.

The results confirm the findings from the previous experiments. In cold conditions, the combination of simplified temperature and salinity profiles leads to brightness temperatures close to reference brightness temperatures for first-year ice, with the set of profiles using the salinity as a function of depth introducing slightly less uncertainty $(3.1 \pm 6.8 \mathrm{~K})$ than the set using constant salinity $(3.4 \pm 7.8 \mathrm{~K}$ ) (Fig. 7, first and third columns). For multiyear ice, the mean absolute difference between the brightness temperatures simulated based on the simplifications and the reference brightness temperatures is clearly lower when using profiles with a salinity as function of depth $(2.5 \pm 2.7 \mathrm{~K})$ than when using constant salinity profiles $(7.0 \pm 4.9 \mathrm{~K})$. 
(a) EXPERIMENT SIMPLEALLCONST

- linear temperature profile

- constant salinity profile (b) EXPERIMENT SIMPLEALLFUNC

- linear temperature profile

- salinity profile as a function of depth
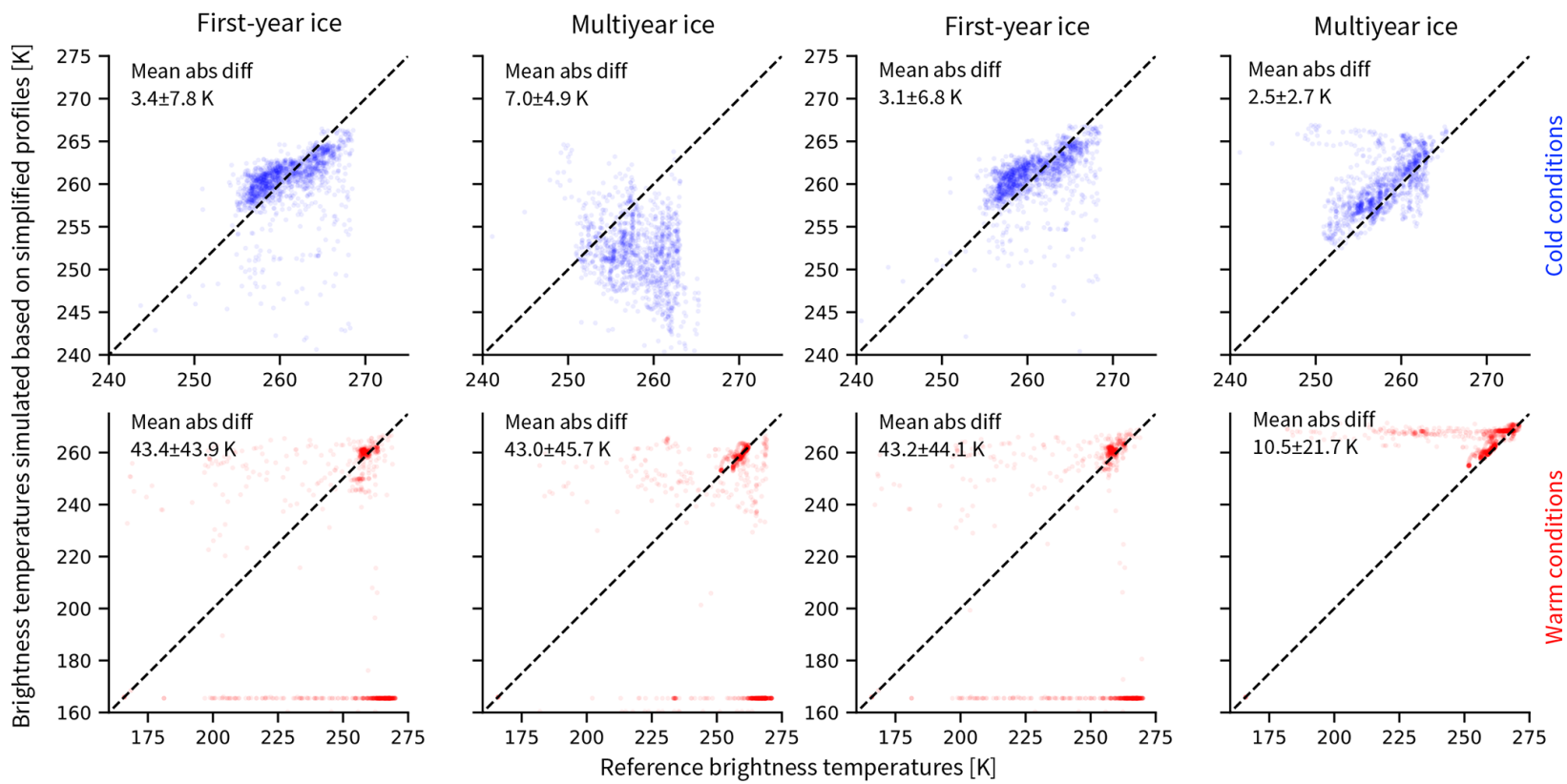

Figure 7. Brightness temperatures at $6.9 \mathrm{GHz}$ vertical polarization, simulated based on two-step linear temperature profiles and (a) constant salinity profiles (experiment SIMPLEALLCONST) or (b) salinity profiles as a function of depth (experiment SIMPLEALLFUNC), as a function of reference brightness temperatures. The first and third columns show first-year ice. The second and fourth columns show multiyear ice. The top row shows cold conditions (October to March), and the bottom row shows warm conditions (April to September). Note that the axes for cold conditions are limited to the range between 240 and $275 \mathrm{~K}$ for clarity. The remaining brightness temperatures are scattered between 165 and $240 \mathrm{~K}$ and represent around $2 \%$ of the simplified data and $0.4 \%$ of the reference data.

In warm conditions, mean absolute differences are an order of magnitude higher than in cold conditions, and similar for first-year ice with both salinity assumptions (43.4 \pm $43.9 \mathrm{~K}$ using constant salinity and $43.0 \pm 44.1 \mathrm{~K}$ using salinity as a function of depth). For multiyear ice, the uncertainty is again clearly lower when using profiles with a salinity as function of depth $(10.5 \pm 21.7 \mathrm{~K})$ than when using constant salinity profiles $(43.0 \pm 45.7 \mathrm{~K})$ (Fig. 7 , second and fourth columns). Reference brightness temperatures and brightness temperatures simulated based on simplified profiles remain clearly different in warm conditions.

In particular, the brightness temperature based on simplified profiles is close or equal to $160 \mathrm{~K}$, i.e., open-water brightness temperatures, at most of the time steps in warm conditions. This is because, in warm conditions, the physical temperature of the ice surface approaches $0{ }^{\circ} \mathrm{C}$, and the closer it gets to $0^{\circ} \mathrm{C}$, the lower the salinity must be in order for dry ice to exist rather than slush. At high temperatures and subsurface salinities above $0 \mathrm{~g} \mathrm{~kg}^{-1}$, as is the case in both salinity simplifications for first-year ice and in the constant salinity simplification for multiyear ice (see Fig. 5), the subsurface brine volume fraction therefore approaches 1 very quickly. At subsurface brine volume fractions near 1, the brightness temperature approaches the brightness temperature of open water, as shown in Sect. 4.1.

Through these experiments, we investigated the effect of the simplification of temperature and salinity profiles on the simulated brightness temperature. A summary of the setup and results of the different experiments can be found in Table 2 . In conclusion, we recommend using a two-step linear temperature profile in snow and ice and an ice salinity profile as a function of depth when simulating brightness temperatures based on GCM output for cold conditions. For warmer and wet subsurface conditions, we recommend exploring possibilities to describe surface and subsurface properties as accurately as possible because the ice subsurface brine volume fraction is the main driver of the simulated brightness temperature.

As the effect of temperature and salinity distribution is now clearer, we turn to another characteristic of GCMs, the limited vertical resolution owing to computational efficiency. Indeed, computing vertical temperature and salinity profiles based on the surface temperature and sea ice thickness given by a GCM adds a vertical dimension to a two-dimensional output. This means that the computation time and power needed by an operator applied to a GCM will be much higher 
Table 2. Summary of the results of the experiments investigating the effect of simplifying temperature and salinity profiles on the brightness temperature simulation. See Sect. 4.2 for more information.

\begin{tabular}{|c|c|c|c|c|c|c|}
\hline \multirow[t]{3}{*}{ Experiment } & \multirow[t]{3}{*}{ Profiles used } & \multirow[t]{3}{*}{ Tools used for profiles } & \multicolumn{4}{|c|}{$\begin{array}{l}\text { Mean absolute difference between reference } \\
\text { and simplified brightness temperatures }[\mathrm{K}]\end{array}$} \\
\hline & & & \multicolumn{2}{|c|}{ Cold conditions } & \multicolumn{2}{|c|}{ Warm conditions } \\
\hline & & & FYI & MYI & FYI & MYI \\
\hline SIMPLETEMP & Reference salinity & $\begin{array}{l}\text { surface temperature as } \\
\text { computed by SAMSIM } \\
\text { and Eq. (A6) } \\
\text { as computed by SAMSIM }\end{array}$ & $2.2 \pm 5.8$ & $1.2 \pm 1.3$ & $14.9 \pm 23.8$ & $10.7 \pm 21.3$ \\
\hline SIMPLESALCONST & $\begin{array}{l}\text { Reference temperature } \\
\text { Constant salinity }\end{array}$ & $\begin{array}{l}\text { as computed by SAMSIM } \\
5 \mathrm{~g} \mathrm{~kg}^{-1} \text { for FYI } \\
1 \mathrm{~g} \mathrm{~kg}^{-1} \text { for MYI }\end{array}$ & $2.5 \pm 6.6$ & $6.6 \pm 4.3$ & $43.0 \pm 44.4$ & $40.6 \pm 45.5$ \\
\hline SIMPLESALFUNC & $\begin{array}{l}\text { Reference temperature } \\
\text { Salinity as } \\
\text { function of depth }\end{array}$ & $\begin{array}{l}\text { as computed by SAMSIM } \\
\text { see Table B1 }\end{array}$ & $2.4 \pm 5.9$ & $2.3 \pm 2.6$ & $43.0 \pm 44.1$ & $28.7 \pm 36.5$ \\
\hline SIMPLEALLCONST & $\begin{array}{l}\text { Linear temperature } \\
\text { Constant salinity }\end{array}$ & $\begin{array}{l}\text { see SIMPLETEMP } \\
\text { see SIMPLESALCONST }\end{array}$ & $3.4 \pm 7.8$ & $7.0 \pm 4.9$ & $43.4 \pm 43.9$ & $43.0 \pm 45.7$ \\
\hline SIMPLEALLFUNC & $\begin{array}{l}\text { Linear temperature } \\
\text { Salinity as } \\
\text { function of depth }\end{array}$ & $\begin{array}{l}\text { see SIMPLETEMP } \\
\text { see SIMPLESALFUNC }\end{array}$ & $3.1 \pm 6.8$ & $2.5 \pm 2.7$ & $43.2 \pm 44.1$ & $10.5 \pm 21.7$ \\
\hline
\end{tabular}

than a one-dimensional setup. We therefore investigate the importance of the vertical resolution in a next step.

\subsection{Reducing the vertical resolution}

Applying an emission model to a GCM consumes a lot of computational power, as the input profiles must be prepared and the emission model has to be applied to many grid cells. In the case of the Arctic Ocean at the MPI-ESM low atmospheric resolution of $1.9^{\circ}$, this would mean, for example, $\approx 4000$ data points per time step. As ocean components in GCMs often have higher horizontal resolution than the atmosphere, this would mean even more computational power is needed when using oceanic variables. Reducing the number of layers for the brightness temperature simulation is a possible aspect that could reduce the computation time. This is the issue we explore in the following.

The simplified profiles used for sensitivity experiments in Sect. 4.2 are interpolated to the same number of layers as the reference profiles, i.e., a variable number of layers depending on the ice thickness between 1 and 100 layers. We now run the brightness temperature simulation with the recommended simplified profile, i.e., linear temperature and salinity as a function of depth, interpolated on 10, 7, 5, and 3 equidistant layers, and compare the results to the reference brightness temperatures. We also include the brightness temperatures from the experiment SIMPLEALLFUNC, which is interpolated to the same number of layers as the reference profiles, as an indicator for the minimal simplified uncertainty in the comparison. We concentrate on cold conditions (October to March), as we have shown that the uncertainty in warm conditions is already very large at high vertical resolution and mainly depends directly on the upper centimeters rather than on properties further inside the ice.

We find that the difference in uncertainty remains small between the reference simplification between 1 and 100 layers and the interpolation on 10,7 , or 5 layers, with the mean uncertainty staying constant at $3.1 \mathrm{~K}$ for first-year ice and varying between 2.4 and $2.5 \mathrm{~K}$ for multiyear ice (see Table 3 ). Using three layers, the uncertainty increases slightly by $0.2 \mathrm{~K}$ for the former and by $0.8 \mathrm{~K}$ for the latter but still remains small. We therefore argue that using as few as 5 layers is as reasonable as using 100 layers for the simulation of simplified brightness temperatures.

\section{Summary and discussion}

\subsection{Brightness temperatures for cold conditions}

We showed that in cold conditions (October to March), we can reproduce realistic sea ice surface brightness temperatures at $6.9 \mathrm{GHz}$ vertical polarization using a two-step linear temperature profile in ice and snow and an ice salinity as a function of depth as input for an emission model. The remaining uncertainty is mainly driven by the simplification of the sea ice salinity distribution. These realistic brightness temperatures can be reproduced with similar uncertainty us- 
Table 3. Absolute mean difference and standard deviation $(\mathrm{K})$ between simplified brightness temperatures simulated based on profiles interpolated on different number of layers and reference brightness temperatures simulated based on profiles covering 1 to 100 layers, depending on the thickness of the ice. These values only represent cold conditions (October to March).

\begin{tabular}{lrrrcc}
\hline & 3 layers & 5 layers & 7 layers & 10 layers & 1 to 100 layers \\
\hline First-year ice & $3.3 \pm 6.9$ & $3.1 \pm 6.8$ & $3.1 \pm 6.8$ & $3.1 \pm 6.8$ & $3.1 \pm 6.8$ \\
Multiyear ice & $3.3 \pm 2.7$ & $2.4 \pm 2.7$ & $2.4 \pm 2.7$ & $2.4 \pm 2.7$ & $2.5 \pm 2.7$ \\
\hline
\end{tabular}

ing as few as five layers. A very high vertical resolution of the ice properties is therefore not needed.

This study was motivated by the fact that observational uncertainty could be reduced by the approach of an observational operator. It is, however, not trivial to evaluate this proposition based on our results. To compare the uncertainty (K) introduced by the brightness temperature simulation to uncertainties (\%) introduced by a sea ice concentration retrieval algorithm, we translate the uncertainty in brightness temperature into uncertainty in sea ice concentration.

A simple retrieval algorithm to retrieve sea ice concentration SIC is given by

$\mathrm{SIC}=\frac{\mathrm{TB}-\mathrm{TB}_{\mathrm{w}}}{\mathrm{TB}_{\mathrm{i}}-\mathrm{TB}_{\mathrm{w}}}$,

with TB the total brightness temperature (ice and open water combined), $\mathrm{TB}_{\mathrm{w}}$ a typical open-water brightness temperature, and $\mathrm{TB}_{\mathrm{i}}$ a typical sea ice brightness temperature. If we introduce uncertainties $\Delta$ SIC and $\Delta \mathrm{TB}$ into the previous equation, this leads to

$\mathrm{SIC}+\Delta \mathrm{SIC}=\frac{\mathrm{TB}+\Delta \mathrm{TB}-\mathrm{TB}_{\mathrm{w}}}{\mathrm{TB}_{\mathrm{i}}-\mathrm{TB}_{\mathrm{w}}}$,

resulting in

$\Delta \mathrm{SIC}=\frac{\Delta \mathrm{TB}}{\mathrm{TB}_{\mathrm{i}}-\mathrm{TB}_{\mathrm{w}}}$.

In our study, we only simulated brightness temperatures of the snow and ice column. To infer an example for $\mathrm{TB}_{\mathrm{i}}$ and $\mathrm{TB}_{\mathrm{w}}$ from our results, we use our finding from Sect. 4.1 that the simulated brightness temperature for ice with low subsurface brine volume fraction is representative of a dry snow and ice column and the simulated brightness temperature for ice with very high subsurface brine volume fraction is comparable to the brightness temperature for open water. From these results we can therefore infer a $\mathrm{TB}_{\mathrm{i}}$, here the simulated brightness temperature for ice with low subsurface brine volume fraction, varying around $263 \mathrm{~K}(263.8 \pm 3.6 \mathrm{~K}$ for first-year ice and $263.7 \pm 4.3 \mathrm{~K}$ for multiyear ice), and a $\mathrm{TB}_{\mathrm{w}}$, here the simulated brightness temperatures at very high subsurface brine volume fractions, varying around $166 \mathrm{~K}$ $(166.1 \pm 0.7 \mathrm{~K}$ for first-year ice and $165.9 \pm 0.1 \mathrm{~K}$ for multiyear ice). Following Eq. (3), in this range spanning approximately $100 \mathrm{~K}$, an uncertainty of $1 \mathrm{~K}$ in brightness temperature at $6.9 \mathrm{GHz}$ vertical polarization therefore approximately translates into $1 \%$ of absolute uncertainty in sea ice concentration. The observational uncertainty of sea ice concentration in cold conditions is up to $2.5 \%$ in consolidated ice and up to $12 \%$ for marginal ice zones (Ivanova et al., 2015). The uncertainty of the simulated brightness temperatures translates to a similar range. This might, at first glance, not appear as a solution to drastically reduce the observational uncertainty. However, an observational operator is consistent in time and space and therefore allows a process understanding of the uncertainties in brightness temperature simulations and, in a possible next step, in retrieval algorithms.

\subsection{Brightness temperatures for warm conditions}

In warm conditions (April to September), we cannot reproduce realistic sea ice surface brightness temperatures due to the very high sensitivity of the subsurface brine volume fraction to small changes in salinity near $0^{\circ} \mathrm{C}$. We therefore recommend using another approach to simulate brightness temperatures for warm conditions. We suggest assuming that the brightness temperature of warm bare ice is similar all over the Arctic, as temperatures are near $0^{\circ} \mathrm{C}$. The surface brightness temperature is a linear combination of the bare ice brightness temperature and the brightness temperature of the melt ponds covering the ice. Therefore, this constant brightness temperature can be combined with open-water brightness temperature, weighted by the fraction of melt ponds forming throughout the warm months. This approach is simple. We have, however, not found any other approach that could come closer to reality as the sensitivities are very high near $0^{\circ} \mathrm{C}$.

Another problematic component when surface temperatures increase towards warm conditions is the snow. While the detailed profile of dry snow is not necessarily needed as long as its presence is taken into account for the thermal insulation of the ice and for the refraction of the radiation, the influence of wet snow on microwave radiation is much larger. Because in the case of melting snow very precise information about the wetness distribution in the snow is needed, we cannot come close to simulating realistic brightness temperatures from GCM output. In our experiments we have ignored this effect by setting the snow wetness to zero at all times. However, for a year-round realistic simulation of brightness temperatures, we suggest excluding data containing melting snow from the brightness temperature simulation. As periods of wet snow due to melting or advection of warm air are typ- 
ically locally limited in time, we argue that our suggestions enable the simulation of brightness temperature simulations over a large amount of the year.

\subsection{Outlook}

The evaluation framework in this study can be used to explore simulated brightness temperatures at higher frequencies, nearer to the most used operational frequencies. However, snow is a limiting factor in this case. While the radiative effect of a dry snow cover is small at $6.9 \mathrm{GHz}$, its impact increases with increasing frequency. It therefore becomes more important to know the snow structure, e.g., snow density, snow temperature, and snow scatterer structure. This information is lacking in GCMs. As the snow structure is more dynamic and changes faster than the ice structure, parametrization for the snow structure do not exist yet to our knowledge. It would be of high interest to explore the evolution of snow on sea ice in more detail and perform sensitivity studies to identify possible simplifications. These could eventually lead to realistic brightness temperatures simulated based on GCM output at higher frequencies than $6.9 \mathrm{GHz}$.

Finally, our analysis focuses on the simulation of brightness temperatures based on output from a GCM that simulates sea ice with a very simple sea ice model. The use of output from GCMs that simulate sea ice with more complex sea ice models might yield lower uncertainty in the brightness temperature simulation. However, although these models compute many physical properties inside the ice, they do not necessarily store them for each time step. Using the more complex properties of these models would therefore require one to build the emission model into the model code, instead of applying an "external" operator to model output that has already produced.

\section{Conclusions}

With the help of a one-dimensional thermodynamic sea ice model and a one-dimensional emission model, we investigated if realistic sea ice brightness temperatures can be simulated based on GCM output at a frequency of $6.9 \mathrm{GHz}$ with vertical polarization. We conclude that it is possible to simulate realistic sea ice brightness temperatures if the time of year and boundary conditions are taken into account. We propose the following structure for an observational operator for sea ice at $6.9 \mathrm{GHz}$ vertical polarization.

\section{Periods of cold conditions.}

- Use the temperature profile provided by the GCM if it exists. Otherwise, use the simulated snow surface temperature and ocean temperature at the bottom of the ice to infer a two-step linear temperature profile through the snow and ice.
- Use the salinity profile provided by the GCM if it exists. Otherwise, interpolate the salinity profile as a function of depth, following the functions given by Griewank and Notz (2015).

- Apply an emission model, e.g., MEMLS, to these profiles, combined with information about correlation length, sea ice type, etc.

- Use sea ice concentration and atmospheric properties provided by the GCM.

- Apply a simple ocean emission model and atmospheric radiative transfer model to account for the influence of open water when the sea ice concentration is below $100 \%$ and for the influence of the atmosphere on the brightness temperature measurements by satellites from space.

Periods of bare ice near $0^{\circ} \mathrm{C}$.

- Use a constant brightness temperature for the ice surfaces. Burgard et al. (2020) derive a warm conditions sea ice surface brightness temperature of $266.78 \mathrm{~K}$ from observational estimates. This represents a brightness temperature at the top of the atmosphere of $262.29 \mathrm{~K}$ corrected by the mean atmospheric effect of $4.49 \mathrm{~K}$ in their simulations.

- Use sea ice concentration, melt pond fraction, and atmospheric properties provided by the GCM.

- Apply a simple ocean emission model and atmospheric radiative transfer model to account for the influence of open water when the sea ice concentration is below $100 \%$ or when melt ponds are present on the ice and for the influence of the atmosphere on the brightness temperature measurements by satellites from space. If it does not exist yet, include a routine accounting for the effect of melt ponds in addition to the effect of openocean surfaces in the surface emission model.

\section{Periods of melting snow.}

- Identify periods and locations of reduction in snow thickness at temperatures near $0{ }^{\circ} \mathrm{C}$ in the GCM output.

- Ignore these points in the analysis. The GCM output does not provide enough information about the snow properties, and wet snow strongly affects the brightness temperature.

The observational operator structure we present here allows us to simulate brightness temperatures from twodimensional output by a GCM that can be compared with brightness temperatures measured by satellites. This opens new possibilities and perspectives for model-to-observation comparison in the Arctic Ocean. 
Appendix A: Retrieving sea ice properties from temperature and salinity

The following formulas were used to compute the ice density $\rho_{\mathrm{i}}$ and brine volume fraction $\Phi_{1}$ profiles from the ice temperature $T$ and salinity $S$ profiles:

$\rho_{0}=916.18-0.1403 T$

where $\rho_{0}$ is the density of pure ice (Pounder, 1965).

$$
S_{\mathrm{b}}=\left\{\begin{array}{c}
508.18+14.535 T+0.2018 T^{2} \\
\text { if } T \in\left[-43.2^{\circ} \mathrm{C},-36.8^{\circ} \mathrm{C}\right] \\
{[\text { Eq. }(39) \text { in Vant et al. }(1978)]} \\
242.94+1.5299 T+0.04529 T^{2} \\
\text { if } T \in\left[-36.8^{\circ} \mathrm{C},-22.9^{\circ} \mathrm{C}\right] \\
{[\text { Eq. }(39) \text { in Vant et al. }(1978)]} \\
-1.20-21.8 T-0.919 T^{2} \\
\text { if } T \in]-22.9^{\circ} \mathrm{C},-8.0^{\circ} \mathrm{C}[ \\
{[\mathrm{Eq} .(3.4) \text { in Notz }(2005)]} \\
1 /(0.001-(0.05411 / T)) \\
\text { if } T \in\left[-8.0^{\circ} \mathrm{C}, 0^{\circ} \mathrm{C}[\right. \\
{[\text { Eq. }(3.5) \text { in } \mathrm{Notz}(2005)]} \\
0 \text { if } T=0
\end{array}\right.
$$

where $S_{\mathrm{b}}$ is the brine salinity.

$\rho_{\mathrm{w}}=1000.3+0.78237 S_{\mathrm{b}}+2.8008 \cdot 10^{-4} S_{\mathrm{b}}^{2}$,

where $\rho_{\mathrm{W}}$ is the density of seawater at $0^{\circ} \mathrm{C}$ (Eq. 3.8 in Notz, 2005).

$\Phi_{1}= \begin{cases}S / S_{\mathrm{b}} & \text { if } S_{\mathrm{b}}>0[\mathrm{Eq} .(1.5) \text { in Notz (2005)] } \\ 1 & \text { if } S_{\mathrm{b}}=0\end{cases}$

$\rho_{\mathrm{i}}=\Phi_{1} \cdot \rho_{\mathrm{w}}+\left(1-\Phi_{1}\right) \cdot \rho_{0}$

The following formula was used to infer the ice surface tem-

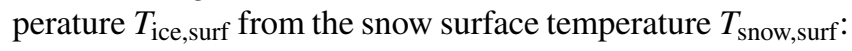

$T_{\text {ice }, \text { surf }}=\frac{T_{\text {snow,surf }} \cdot \frac{k_{\mathrm{s}}}{h_{\mathrm{s}}}+T_{\text {bottom }} \cdot \frac{k_{\mathrm{i}}}{h_{\mathrm{i}}}}{\frac{k_{\mathrm{s}}}{h_{\mathrm{s}}}+\frac{k_{\mathrm{i}}}{h_{\mathrm{i}}}}$,

where $k_{\mathrm{S}}$ is the thermal conductivity of snow $\quad=$ $\left.0.31 \mathrm{WK}^{-1} \mathrm{~m}^{-1}\right), k_{\mathrm{i}}$ is the thermal conductivity of ice (= $\left.2.17 \mathrm{WK}^{-1} \mathrm{~m}^{-1}\right), h_{\mathrm{s}}$ is the snow thickness, $h_{\mathrm{i}}$ is the ice thickness, and $T_{\text {bottom }}$ is the temperature at the bottom of the ice, which is set to $-1.8^{\circ} \mathrm{C}$. 
Appendix B: Salinity parametrization as a function of depth

Table B1. Formulas describing salinity as a function of depth, from Griewank and Notz (2015), as shown in the solid lines in Fig. 5.

\begin{tabular}{lll}
\hline Ice type & $\begin{array}{l}\text { Salinity parametrization } \\
\text { as a function of depth } z\end{array}$ & Constants needed \\
\hline First-year ice $S_{\mathrm{fy}}$ & $\frac{z}{a+b z}+c$ & $\begin{array}{l}a=1.0964, b=-1.0552, \\
c=4.41272\end{array}$ \\
\hline Multiyear ice $S_{\mathrm{my}}$ & $\frac{z}{a}+\left(\frac{z}{b}\right)^{1 / c}$ & $\begin{array}{l}a=0.17083, b=0.92762, \\
c=0.024516\end{array}$ \\
\hline $\begin{array}{l}\text { Transition } \\
\text { first-year to } \\
\text { multiyear ice }\end{array}$ & $(1-t) \cdot S_{\mathrm{my}}(z)+t \cdot S_{\mathrm{fy}}(z)$ & $\begin{array}{l}t=0 \text { at start of melt season and } \\
t=1 \text { at start of freezing season }\end{array}$ \\
\hline
\end{tabular}


Code and data availability. Primary data and scripts used in this study are archived by the Max Planck Institute for Meteorology and can be obtained by contacting publications@mpimet.mpg.de.

Author contributions. CB carried out all analyses and wrote the manuscript. DN and LTP developed the original idea. CB, DN, LTP and RTT contributed to discussions.

Competing interests. The authors declare that they have no conflict of interest.

Acknowledgements. We thank Stefan Kern for constructive comments and discussions. We also thank Mohammed Shokr and an anonymous reviewer for the detailed and constructive comments.

Financial support. This research has been funded by the European Space Agency (Sea Ice Climate Change Initiative Phase 2).

The article processing charges for this open-access publication were covered by the Max Planck Society.

Review statement. This paper was edited by Ludovic Brucker and reviewed by Mohammed Shokr and one anonymous referee.

\section{References}

Bailey, D., DuVivier, A., Holland, M., Hunke, E., Lipscomb, B., Briegleb, B., Bitz, C., and Schramm, J.: CESM CICE5 Users Guide, Tech. rep., 2018.

Barber, D., Fung, A., Grenfell, T., Nghiem, S., Onstott, R., Lytle, V., Perovich, D., and Gow, A.: The role of snow on microwave emission and scattering over first-year sea ice, IEEE T. Geosci. Remote, 36, 1750-1763, https://doi.org/10.1109/36.718643, 1998.

Bunzel, F., Notz, D., Baehr, J., Müller, W., and Fröhlich, K.: Seasonal climate forecasts significantly affected by observational uncertainty of Arctic sea ice concentration, Geophys. Res. Lett., 43, 852-859, https://doi.org/10.1002/2015GL066928, 2016.

Burgard, C., Notz, D., Pedersen, L. T., and Tonboe, R. T.: The Arctic Ocean Observation Operator for $6.9 \mathrm{GHz}$ (ARC3O) - Part 2: Development and evaluation, The Cryosphere, 14, 2387-2407, https://doi.org/10.5194/tc-14-2387-2020, 2020.

Dee, D., Uppala, S., Simmons, A., Berrisford, P., Poli, P., Kobayashi, S., Andrae, U., Balmaseda, M., Balsamo, G., Bauer, P., Bechtold, P., Beljaars, A., van de Berg, L., Bidlot, J., Bormann, N., Delsol, C., Dragani, R., Fuentes, M., Geer, A., Haimberger, L., Healy, S., Hersbach, H., Holm, E., Isaksen, L., Kållberg, P., Köhler, M., Matricardi, M., McNally, A., MongeSanz, B., Morcrette, J.-J., Park, B.-K., Peubey, C., de Rosnay, P., Tavolato, C., Thébaut, J.-N., and Vitart, F.: The ERAInterim reanalysis: configuration and performance of the data assimilation system, Q. J. Roy. Meteor. Soc., 137, 553-597, https://doi.org/10.1002/qj.828, 2011.
Eyring, V., Cox, P., Flato, G., Gleckler, P., Abramowitz, G., Caldwell, P., Collins, W., Gier, B., Hall, A., Hoffman, F., Hurtt, G., Jahn, A., Jones, C., Klein, S., Krasting, J., Kwiatkowski, L., Lorenz, R., Maloney, E., Meehl, G., Pendergrass, A., Pincus, R., Ruane, A., Russell, J., Sanderson, B., Santer, B., Sherwood, S., Simpson, I., Stouffer, R., and Williamson, M.: Taking climate model evaluation to the next level, Nat. Clim. Change, 9, 102110, https://doi.org/10.1038/s41558-018-0355-y, 2019.

Flato, G., Marotzke, J., Abiodun, B., Braconnot, P., Chou, S., Collins, W., Cox, P., Driouech, F., Emori, S., Eyring, V., Forest, C., Gleckler, P., Guilyardi, E., Jakob, C., Kattsov, V., Reason, C., and Rummukainen, M.: Evaluation of Climate Models, book section 9, Cambridge University Press, Cambridge, United Kingdom and New York, NY, USA, 741-866, https://doi.org/10.1017/CBO9781107415324.020, 2013.

Gabarro, C., Turiel, A., Elosegui, P., Pla-Resina, J. A., and Portabella, M.: New methodology to estimate Arctic sea ice concentration from SMOS combining brightness temperature differences in a maximum-likelihood estimator, The Cryosphere, 11, 19872002, https://doi.org/10.5194/tc-11-1987-2017, 2017.

Giorgetta, M., Roeckner, E., Mauritsen, T., Bader, J., Crueger, T., Esch, M., Rast, S., Kornblueh, L., Schmidt, H., Kinne, S., Hohenegger, C., Möbis, B., Krismer, T., Wieners, K., and Stevens, B.: The atmospheric general circulation model ECHAM6: Model description, Tech. Rep. Reports on Earth System Science, 135/2013, Max Planck Institute for Meteorology, 2013.

Gregory, J., Stott, P., Cresswell, D., Rayner, N., Gordon, C., and Sexton, D.: Recent and future changes in Arctic sea ice simulated by the HadCM3 AOGCM, Geophys. Res. Lett., 29, 28-1-28-4, https://doi.org/10.1029/2001GL014575, 2002.

Grenfell, T., Barber, D., Fung, A., Gow, A., Jezek, K., Knapp, E., Nghiem, S., Onstott, R., Perovich, D., Roesler, C., Swift, C., and Tanis, F.: Evolution of electromagnetic signatures of sea ice from initial formation to the establishment of thick first-year ice, IEEE T. Geosci. Remote, 36, 1642-1654, https://doi.org/10.1109/36.718636, 1998.

Griewank, P. and Notz, D.: Insights into brine dynamics and sea ice desalination from a 1-D model study of gravity drainage, J. Geophys. Res.-Oceans, 118, 3370-3386, https://doi.org/10.1002/jgrc.20247, 2013.

Griewank, P. J. and Notz, D.: A 1-D modelling study of Arctic sea-ice salinity, The Cryosphere, 9, 305-329, https://doi.org/10.5194/tc-9-305-2015, 2015.

Hallikainen, M.: Microwave radiometry of snow, Adv. Space Res., 9, 267-275, https://doi.org/10.1016/0273-1177(89)904948, 1989 .

Huwald, H., Tremblay, L.-B., and Blatter, H.: Reconciling different observational data sets from Surface Heat Budget of the Arctic Ocean (SHEBA) for model validation purposes, J. Geophys. Res.-Oceans, 110, c05009, https://doi.org/10.1029/2003JC002221, 2005.

Hwang, B., Ehn, J., Barber, D., Galley, R., and Grenfell, T.: Investigations of newly formed sea ice in the Cape Bathurst polynya: 2. Microwave emission, J. Geophys. Res.-Oceans, 112, C05003, https://doi.org/10.1029/2006JC003703, 2007.

Ivanova, N., Johannessen, O. M., Pedersen, L. T., and Tonboe, R. T.: Retrieval of Arctic Sea Ice Parameters by Satellite Passive Microwave Sensors: A Comparison of Eleven Sea Ice Con- 
centration Algorithms, IEEE T. Geosci. Remote, 52, 7233-7246, https://doi.org/10.1109/TGRS.2014.2310136, 2014.

Ivanova, N., Pedersen, L. T., Tonboe, R. T., Kern, S., Heygster, G., Lavergne, T., Sørensen, A., Saldo, R., Dybkjær, G., Brucker, L., and Shokr, M.: Inter-comparison and evaluation of sea ice algorithms: towards further identification of challenges and optimal approach using passive microwave observations, The Cryosphere, 9, 1797-1817, https://doi.org/10.5194/tc9-1797-2015, 2015.

JAXA: Global Change Observation Mission: Third Research Announcement, Tech. rep., Earth Observation Research Center, Japan Aerospace Exploration Agency, Japan, 2011.

Jezek, K., Perovich, D., Golden, K., Luther, C., Barber, D., Gogineni, P., Grenfell, T., Jordan, A., Mobley, C., Nghiem, S., and Onstott, R.: A broad spectral, interdisciplinary investigation of the electromagnetic properties of sea ice, IEEE T. Geosci. Remote, 36, 1633-1641, https://doi.org/10.1109/36.718635, 1998.

Lavergne, T., Sørensen, A. M., Kern, S., Tonboe, R., Notz, D., Aaboe, S., Bell, L., Dybkjær, G., Eastwood, S., Gabarro, C., Heygster, G., Killie, M. A., Brandt Kreiner, M., Lavelle, J., Saldo, R., Sandven, S., and Pedersen, L. T.: Version 2 of the EUMETSAT OSI SAF and ESA CCI sea-ice concentration climate data records, The Cryosphere, 13, 49-78, https://doi.org/10.5194/tc-13-49-2019, 2019.

Lee, S.-M., Sohn, B.-J., and Kim, S.-J.: Differentiating between first-year and multiyear sea ice in the Arctic using microwaveretrieved ice emissivities, J. Geophys. Res.-Atmos., 122, 50975112, https://doi.org/10.1002/2016JD026275, 2017.

Lemmetyinen, J., Derksen, C., Rott, H., Macelloni, G., King, J., Schneebeli, M., Wiesmann, A., Leppännen, L., Kontu, A., and Pulliainen, J.: Retrieval of Effective Correlation Length and Snow Water Equivalent from Radar and Passive Microwave Measurements, Remote Sensing, 10, 170, https://doi.org/10.3390/rs10020170, 2018.

Li, C., Notz, D., Tietsche, S., and Marotzke, J.: The Transient versus the Equilibrium Response of Sea Ice to Global Warming, J. Climate, 26, 5624-5636, https://doi.org/10.1175/JCLI-D-1200492.1, 2013.

Mahlstein, I. and Knutti, R.: September Arctic sea ice predicted to disappear near $2{ }^{\circ} \mathrm{C}$ global warming above present, J. Geophys. Res., 117, D06104, https://doi.org/10.1029/2011JD016709, 2012.

Mätzler, C.: Applications of the interaction of microwaves with the natural snow cover, Remote Sensing Reviews, 2, 259-387, https://doi.org/10.1080/02757258709532086, 1987.

Mätzler, C.: Relation between grain size and correlation length of snow, J. Glaciol., 48, 461-466, https://doi.org/10.3189/172756502781831287, 2002.

Nakawo, M. and Sinha, N.: Growth Rate and Salinity Profile of First-Year Sea Ice in the High Arctic, J. Glaciol., 27, 315-330, https://doi.org/10.3189/S0022143000015409, 1981.

NASDA: AMSR-E Data Users Handbook, Tech. Rep. NCX030021, Earth Observation Center, National Space Development Agency of Japan, Japan, 2003.

Niederdrenk, A. and Notz, D.: Arctic sea ice in a $1.5^{\circ} \mathrm{C}$ warmer world, Geophys. Res. Lett., 45, 1963-1971, https://doi.org/10.1002/2017GL076159, 2018.

Notz, D.: Thermodynamic and Fluid-Dynamical Processes in Sea Ice, $\mathrm{PhD}$ thesis, University of Cambridge, 2005.
Notz, D. and Stroeve, J.: Observed Arctic sea-ice loss directly follows anthropogenic $\mathrm{CO}_{2}$ emission, Science, 354, 767-750, https://doi.org/10.1126/science.aag2345, 2016.

Notz, D., Haumann, A., Haak, H., and Marotzke, J.: Arctic seaice evolution as modeled by Max Planck Institute for Meteorology's Earth system model, J. Adv. Model Earth Sy., 5, 173-194, https://doi.org/10.1002/jame.20016, 2013.

Perovich, D., Longacre, J., Barber, D., Maffione, R., Cota, G., Mobley, C., Gow, A., Onstott, R., Grenfell, T., Pegau, W., Landry, M., and Roesler, C.: Field observations of the electromagnetic properties of first-year sea ice, IEEE T. Geosci. Remote, 36, 17051715, https://doi.org/10.1109/36.718639, 1998.

Pounder, E.: The Physics of Ice, Elsevier, 1st Edn., 1965.

Proksch, M., Löwe, H., and Schneebeli, M.: Density, specific surface area, and correlation length of snow measured by highresolution penetrometry, J. Geophys. Res.-Earth, 120, 346-362, https://doi.org/10.1002/2014JF003266, 2015.

Ridley, J., Lowe, J., and Hewitt, H.: How reversible is sea ice loss?, Cryosphere, 6, 193-198, https://doi.org/10.5194/tc-6-193-2012, 2012.

Shokr, M. and Sinha, N.: Sea ice Properties: Data and Derivations, in: Sea Ice: Physics and Remote Sensing, Geophysical Monograph 209, 1st Edn., American Geophysical Union, chap. 3, John Wiley \& Sons, Inc., 99-137, 2015a.

Shokr, M. and Sinha, N.: Remote Sensing Principles Relevant to Sea Ice, in: Sea Ice: Physics and Remote Sensing, Geophysical Monograph 209, 1st Edn., American Geophysical Union, chap. 7, John Wiley \& Sons, Inc., 271-335, 2015 b.

Tonboe, R.: The simulated sea ice thermal microwave emission at window and sounding frequencies, Tellus, 62A, 333-344, https://doi.org/10.1111/j.1600-0870.2010.00434.x, 2010.

Tonboe, R., Andersen, S., Toudal, L., and Heygster, G.: Sea ice emission modelling, in: Thermal Microwave Radiation - Applications for Remote Sensing, edited by: Mätzler, C., Rosenkranz, P., Battaglia, A., and Wigneron, J., IET Electromagnetic Waves Series 52, 382-400, 2006.

Tonboe, R., Dybkjaer, G., and Højer, J.: Simulations of the snow covered sea ice surface temperature and microwave effective temperature, Tellus, 63A, 1028-1037, https://doi.org/10.1111/j.1600-0870.2011.00530.x, 2011.

Tonboe, R. T., Eastwood, S., Lavergne, T., Sørensen, A. M., Rathmann, N., Dybkjær, G., Pedersen, L. T., Høyer, J. L., and Kern, S.: The EUMETSAT sea ice concentration climate data record, The Cryosphere, 10, 2275-2290, https://doi.org/10.5194/tc-102275-2016, 2016.

Ulaby, F., Moore, R., and Fung, A.: Passive microwave sensing of the ocean, in: Microwave Remote Sensing, Active and Passive Volume III, From Theory to Applications, chap. 18, Artech House, Inc., 1412-1521, 1986.

Vancoppenolle, M., Fichefet, T., Goosse, H., Bouillon, S., Madec, G., and Morales Maqueda, M.: Simulating the mass balance and salinity of Arctic and Antarctic sea ice. 1. Model description and validation, Ocean Model., 27, 33-53, https://doi.org/10.1016/j.ocemod.2008.10.005, 2009.

Vant, M., Ramseier, R., and Makios, V.: The complex-dielectric constant of sea ice at frequencies in the range $0.1-40 \mathrm{GHz}, \mathrm{J}$. Appl. Phys., 49, 1264-1280, https://doi.org/10.1063/1.325018, 1978. 
Wetzel, P., Haak, H., Jungclaus, J., and Maier-Reimer, E.: The MaxPlanck-Institute Global Ocean/Sea-Ice Model MPI-OM, Tech. rep., Max Planck Institute for Meteorology, 2012.

Wiesmann, A. and Mätzler, C.: Microwave emission model of layered snowpacks, Remote Sens. Environ., 70, 307-316, 1999.

Willmes, S., Nicolaus, M., and Haas, C.: The microwave emissivity variability of snow covered first-year sea ice from late winter to early summer: a model study, The Cryosphere, 8, 891-904, https://doi.org/10.5194/tc-8-891-2014, 2014.
Winebrenner, D., Bredow, J., Fung, A., Drinkwater, M., Nghiem, S., Gow, A., Perovich, D., Grenfell, T., Han, H., Kong, J., Lee, J., Mudaliar, S., Onstott, R., Tsang, L., and West, R.: Microwave Sea Ice Signature Modeling, in: Microwave Remote Sensing of Sea Ice, edited by: Carsey, F., chap. 8, American Geophysical Union, 137-175, 1992.

Winton, M.: Do Climate Models Underestimate the Sensitivity of Northern Hemisphere Sea Ice Cover?, J. Climate, 24, 39243934, https://doi.org/10.1175/2011JCLI4146.1, 2011. 